
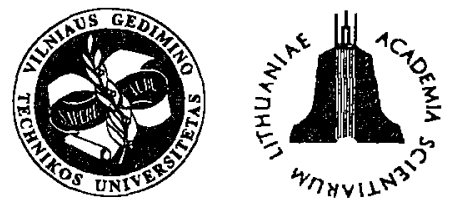

ISSN 1648-4142 TRANSPORT

http:/www.vtu.lt/english/editions

\title{
THE RESEARCH OF DIESEL INJECTION PUMPS PERFORMANCE ON BIOFUEL WITH DIFFERENT VISCOSITY RATE
}

\author{
Gvidonas Labeckas, Stasys Slavinskas \\ Transport and Power Machinery Department, Lithuanian University of Agriculture \\ Studentu g.15, Akademija, LT-4324 Kaunas region,Lithuania,Tel.(37) 397-811,E-mail: gvidonas@info.lzua.lt
}

Received 200205 20; accepted 20020517

\begin{abstract}
The main purpose of this research work is to determine the influence of fuel viscosity on the performance of diesel injection pumps of different design in order to clear up some of the changes in fuel feeding when running them in accordance with governor characteristics on the biofuel derived from vegetable oil.

The given fuel temperature/viscosity relationships and dependencies of fuel feeding on its viscosity applying biofuel on different injection pumps can be practically useful for adjusting them for the work on bio-diesel. According to the analysis of the got results the in-line diesel injection pumps are more suitable for their adaptation for the work on bio-diesel. In this case only small adjustments of biofuel feeding rate are needed.
\end{abstract}

Keywords: diesel engine, injection pump, biofuel, density, viscosity, delivery rate.

\section{Introduction}

The resources of crude oil in the earth deposits are limited. This is one of the main reasons why humanity is imposed to think about the advantages which the usage in internal combustion engines of renewable fuel sources derived from vegetable oil gives. The next reason why population must use biofuel is related to the ecological situation - biofuel at least partly will assist solving the actual problems of reduction carbon dioxide in atmosphere and global warming [1]. Without mentioned reasons biofuel promotion initiative creates new job places and agricultural production sector tends to technical crops growing and processing. So biofuel has undeniable advantages, but nevertheless it has also certain specific properties which differ from diesel fuel.

The analysis of bench testing results shows that applying Rape Oil Methyl Ester (RME) on diesel engines, fuel consumption in mass units increases $12-15 \%$ [1-4]. It depends finally on the engine load and frequency of crankshaft revolutions. Bearing in mind that density of RME is roughly about $7 \%$ higher in comparison with diesel fuel, it is possible to assume that volumetric biofuel consumption rate increases $5-8 \%$. It means that a fuel injection pump without additional adjustments delivers correspondingly enhanced volumetric portions of fuel.

\section{Purpose of the Research}

Changeable kinematic viscosity of fuel not adequately influences the quantity of injected per stroke fuel because of its different impact on high-pressure chamber charging efficiency of the sections and leakages through the clearance in a plunger-barrel unit.

The flow of fuel through high pressure lines can be described by the equations of movement continuity and flow $[5,6]$ :

$$
\begin{aligned}
& \frac{\partial p}{\partial x}+\rho_{d} \frac{\partial c}{\partial t}+\rho_{d} k c=0 \\
& \frac{\partial c}{\partial x}+\frac{1}{a^{2} \rho_{d}} \frac{\partial p}{\partial t}=0
\end{aligned},
$$

where $p$ - fuel pressure in the pipe; $c$ - fuel flow speed inside high pressure pipe; $\rho_{d}-$ fuel density; $a-$ velocity of pressure wave propagation in compressed fuel; $k-$ coefficient which appreciates hydraulic resistance of the fuel delivery system:

$$
k=\frac{0.158}{\operatorname{Re}^{0.25} \frac{c}{d_{v}},}
$$

where $\operatorname{Re}=-\frac{c d_{v}}{v}-$ Reinold's number; $d_{v}$-internal diameter of high pressure fuel delivery pipe; $v-$ kinematic viscosity of the fuel.

As we can notice from the analysis of equations (1, 2) fuel injection characteristics are significantly influenced by the physical properties of the fuel - especially by its density and kinematic viscosity. The difference between RME and diesel fuel actualises itself exactly on the basis of higher density and viscosity [2]. These two factors may have influence on the hydraulic wastes of the injection 
system and fuel charging efficiency to high-pressure chamber above plunger, on quantity of the fuel that leaks out through a clearance in plunger-barrel assembly and fuel injection pressures. The formation of fuel spouts and their spreading across the combustion chamber dynamic as well as the preparation quality of combustible fuel-air mixture largely depend on the level of injection pressure and fuel viscosity rate. In accordance with the acoustic laws velocity and time of pressure wave propagation in the injection line (velocity of sound) that is the actual start of fuel injection process also depends on fuel physical properties.

The quantity of the fuel that leaks out through the clearance between the plunger and the barrel assembly is evaluated by the equation $[6]$ :

$$
z_{1}=\frac{\pi d_{p}\left(\delta_{p}+B p_{s}\right)^{3} \beta_{1} p_{s}^{2} \ln c}{12 l_{p} \mu_{d}\left(c^{p_{s}}-1\right)},
$$

where $l_{p}$ - length of sealing surface of plunger; $d_{p}-$ diameter of plunger; $\delta_{p}$ - radial clearance in plunger and barrel assembly; $B$ - coefficient that evaluates construction and materials of plunger-barrel unit; $p_{s}$ - fuel pressure in the chamber above plunger; $\beta_{f}$ - coefficient that evaluates deviation of plunger geometrical measurements from ideal cylinder form; $\mu_{d}$-kinematic viscosity of the fuel.

The quantity of the fuel that leaks out through the clearance between the nozzle needle and the injector body is estimated as follows [6]:

$$
z_{2}=\frac{\pi d_{a} \delta_{a}{ }^{3} \beta_{2} p_{p}^{2} \ln c}{12 l_{a} \mu_{d}\left(c^{p_{p}}-1\right)},
$$

where $l_{a}$ - length of the sealing surface of the nozzle needle; $d_{a}$ - diameter of the nozzle needle; $\delta_{a}$ - radial clearance between the nozzle needle and the injector body; $p_{p}$ - fuel pressure that acts the nozzle needle sealing cone; $\beta_{2}$ - coefficient that evaluates deviations of geometrical nozzle needle measurements from ideal cylinder form;

The purpose of this research work is to investigate the influence of the fuel viscosity on the performance of diesel injection pumps of different types and design in order to clear up some of fuel delivery changes in governor characteristics applying the biofuel with various viscosity rates.

\section{Research Objects and Methods}

The research work has been done with four sorts of fuel with different viscosity index - diesel fuel, RME, pure rape oil (RO) and RO mixture with diesel fuel ( $25 \% \mathrm{RO}+75$ $\% \mathrm{D})$. One of the critical factors to be considered in this work is fuel temperature and its kinematic viscosity relationship which is presented in logarithmic (lg) scale in Fig 1 for the tested sorts of fuel.

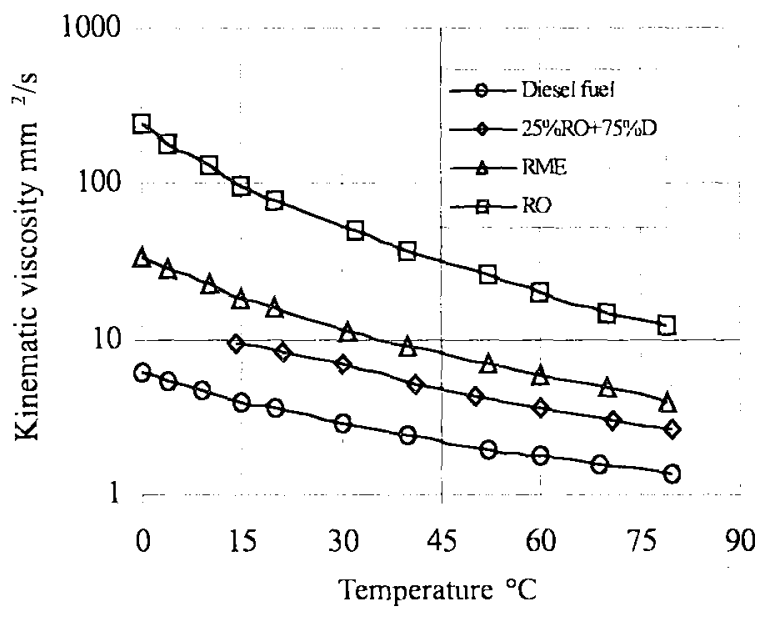

Fig 1. Fuel kinematic viscosity and temperature relationship

The fuel kinematic viscosity was measured by capillary viscometers [7]. The analysis of graphics shows that when temperature rises up kinematic viscosity of the biofuel drops down faster than in the case of diesel fuel. However in spite of this the viscosity of warmed RME and especially pure $\mathrm{RO}$ remains higher than that of diesel fuel. In order to get a sort of the biofuel with kinematic viscosity lower than RME but at the same time, higher than diesel fuel, we decided to choose the mixture compiled of $25 \%$ $\mathrm{RO}+75 \% \mathrm{D}$.

The basic technical data of the fuel injection pumps

\begin{tabular}{|l|c|c|c|}
\hline \multicolumn{1}{|c|}{$\begin{array}{c}\text { Trade-mark of } \\
\text { injection pump }\end{array}$} & UTN-5 & ND-21/4 & VE 4/9 \\
\hline $\begin{array}{l}\text { Type of pump } \\
\text { Governor type } \\
\text { Plunger diameter, } \\
\text { mm }\end{array}$ & $\begin{array}{l}\text { In-Line } \\
\left.\mathrm{m}, \mathrm{v}^{1}\right)\end{array}$ & $\begin{array}{l}\text { Distributor } \\
\left.\mathrm{m}, \mathrm{v}^{1}\right)\end{array}$ & $\begin{array}{l}\text { Distributor } \\
\left.\mathrm{m}^{2} \mathrm{~m}^{2}\right)\end{array}$ \\
$\begin{array}{l}\text { Plunger stroke, } \mathrm{mm} \\
\text { Rated speed, } \mathrm{min}^{-1}\end{array}$ & 8 & 9 & 9 \\
\hline
\end{tabular}

1) mechanical variable-speed; 2) mechanical minimum-maximumspeed

The research work was performed with three different types of the fuel injection pumps: in-line type pump UTN5 produced in fuel equipment manufacture in Noginsk (Russia), distributor type pump ND-21/4 manufactured byfuel equipment company in Vilnius (Lithuania) and Bosch firm distributor type fuel pump VE 4/9. All of them were equipped with mechanical governors (Table). The tested injection pumps are designed for the agriculture purpose tractors D-50, D-144 and for light personal cars VW diesel engines correspondingly.

The research work has been done on the diesel injection pumps checking and adjusting stand Motorpal NC $108-1291$. During the tests fuel pressures developed by a supply pump and quantities of fuel which were delivered per chosen number of injection strokes through every of four injection units were measured. As a result 
governor characteristics of injection pumps were obtained while running them on biofuel with different viscosity rate. The camshaft rotation frequency of the injection pumps was changed from the point which corresponds to diesel engine starting revolutions $\left(100 \mathrm{~min}^{-1}\right)$ up to its highest speed which occurs at the absolute fuel delivery shutting-off point. The fuel temperature during testing procedures was kept at permanent $20^{\circ} \mathrm{C}$ level.

\section{The Obtained Results}

Governor characteristics of the fuel injection pumps are presented on the graphics of Figs 2, 3 and 4. They reflect the dependencies of average fuel quantity being injected per stroke at different camshaft revolutions on kinematic viscosity of the fuel. As we can notice on the graphics, as far as kinematic viscosity of the biofuel increases up to a certain level, the average quantity of the fuel being injected per stroke with all tested pumps also increases.

As far as kinematic viscosity of the fuel increases from $3,6 \mathrm{~mm}^{2} / \mathrm{s}$ (diesel fuel) to $15,8 \mathrm{~mm}^{2} / \mathrm{s}$ (RME) fuel delivery rate per stroke for an in-line type injection pump UTN-5 (Fig 2) increases from 2,30\% $\left(n_{c}=600 \mathrm{~min}^{-1}\right)$ to $2,96 \%\left(n_{c}=400 \mathrm{~min}^{-1}\right)$. It means that fuel delivery rate increases from 0,115 to $0,400 \mathrm{~mm}^{3} /$ cycle for every additional kinematic viscosity unit $\left(\mathrm{mm}^{2} / \mathrm{s}\right)$. The main reason of the increased fuel delivery while running on RME can be related with higher viscosity and pressure that develops in a plunger-type fuel supply pump, better high-pressure chamber above the plunger charging conditions and smaller leakages through a plunger-barrel clearance.

However while applying pure RO, a in-line injection pump UTN-5 which kinematic viscosity at $20^{\circ} \mathrm{C}$ reaches $78,5 \mathrm{~mm}^{2} / \mathrm{s}$ (Fig 1), the fuel delivery per stroke across the whole governor characteristic alternation zone decreases

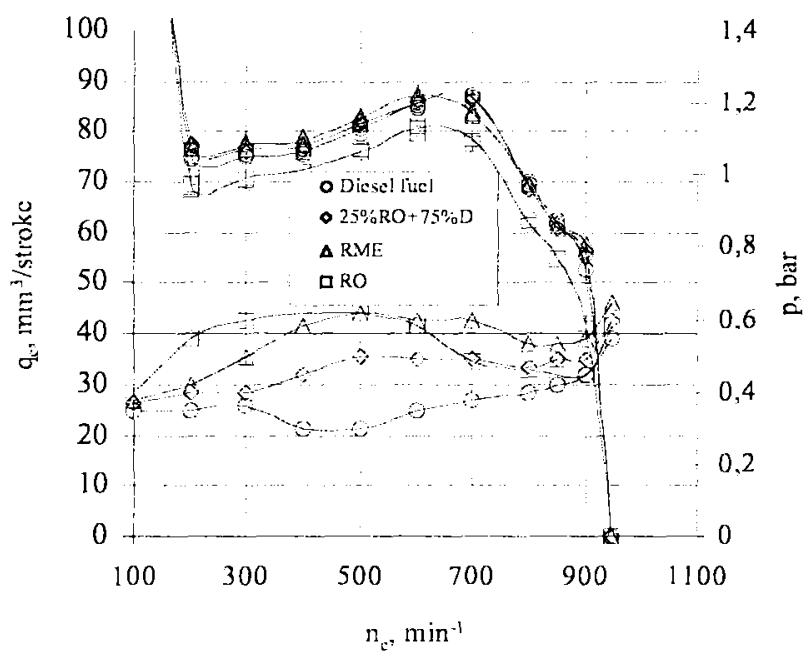

Fig 2. Governor characteristics of an in-line type fuel injection pump UTN-5
$4,7-11,7 \%$. The biggest decrease of fuel delivery while running on pure $\mathrm{RO}$ was received on rated camshaft revolutions frequency $\left(n_{c}=850 \mathrm{~min}^{-1}\right)$. The influence of the fuel viscosity reveals itself even more when a camshaft of the injection pump rotates at the speed which corresponds to the engine full-load point at torque curve maximum $\left(n_{c}=700 \mathrm{~min}^{-1}\right)$. At this critical point the fuel viscosity influence is noticeable even when the injection pump runs on less viscous RME, the fuel delivery per stroke decreases $3,19 \%$. This can be related with the marginal fuel viscosity level and worse plunger-barrel sections charging conditions. The viscosity influence is especially noticeable at the boosted pump speed and fullload fuel delivery zone because charging pressure of the supply system remains at a low level $(0,3-0,6$ bar $)$.

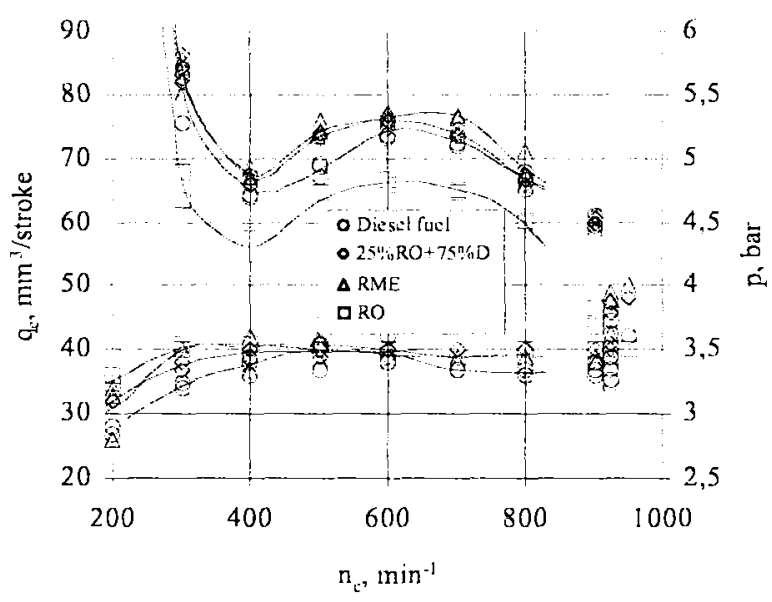

Fig 3. Governor characteristics of a distributor type fuel injection pump ND-21/4

Analysing the performance peculiarities of a fuel injection pump of a distributor type ND-21/4 while running it on the biofuel with various viscosity rate, one must bear in mind four times higher recurrence of the process in comparison with an in-line type pump, correspondingly. shorter high-pressure chamber charging duration and about ten times higher boosted fuel charging pressure from the supply system (Fig 3). As in the case with an inline pump UTN-5, when camshaft revolution frequency decreases below engine rated speed and torque-control unit boosts the quantity of the fuel to be injected, biofuel viscosity influence becomes even more evident. In the case of a distributor type injection pump ND-21/4 the replacement of diesel fuel by $\mathrm{RME}$ leads to the increase of biofuel delivery rate in the torque-control zone from $2,25 \%$ $\left(n_{c}=800 \mathrm{~min}^{-1}\right)$ to $9,02 \%\left(n_{c}=500 \mathrm{~min}^{-1}\right)$. It means that the increase of the fuel kinematic viscosity results in rising of its delivery rate 0,123 and $0.510 \mathrm{~mm}^{3} /$ stroke per every $\left(1 \mathrm{~mm}^{2} / \mathrm{s}\right)$ unit of viscosity correspondingly. Because of the shorter chamber above plunger charging duration $(0,016-0,026 \mathrm{~s})$ and significant influence on the charging process of enlarged kinematic viscosity of pure $\mathrm{RO}$, fuel delivery rate decreases in comparison with an in-line pump 
even more rapidly $(7,1-24,7 \%)$. In the same manner as with UTN-5 the fuel delivery per stroke decreases more evidently when running the pump at boosted camshaft speed $\left(n_{c}=900 \mathrm{~min}^{-1}\right)$.

In a distributor type fuel injection pump VE 4/9 the integrated vane-type supply pump delivers fuel through a pressure-control valve which ensures that the housing pressure rises linearly from $1-2$ to $8-9$ bar as function of camshaft rotating speed that alternates from 100 to $2500 \mathrm{~min}^{-1}$ (Fig 4). In spite of higher fuel gauge pressure and dissimilar design of rotary VE injection pump, viscosity influence on the biofuel delivery rate in a wide range of governor characteristic remains almost unchangeable. After the replacing of diesel fuel with $\mathrm{RME}$, the biofuel delivery rate per stroke of VE pump increases from $1,3 \%$ $\left(n_{c}=2000 \mathrm{~min}^{-1}\right)$ to $9,3 \%\left(n_{c}=500 \mathrm{~min}^{-1}\right)$ or - from 0,031 to $0,166 \mathrm{~mm}^{3} /$ stroke for everyone fuel viscosity unit correspondingly. While applying pure RO, in VE 4/9 pump the biofuel delivery per stroke decreases mostly (7 - 10\%) also at the camshaft rotation frequency which corresponds engine torque-control (unit action) zone. Using the biofuel (RME or RO) instead of diesel fuel, gauge pressure developed by a vane-type supply pump increases wellhigh 1 bar. This fuel gauge pressure directly controls the timing device in the VE pump housing that advances the start of the fuel delivery as the engine speed increases. It means that while running on the biofuel, the actual fuel injection angle also slightly advances.

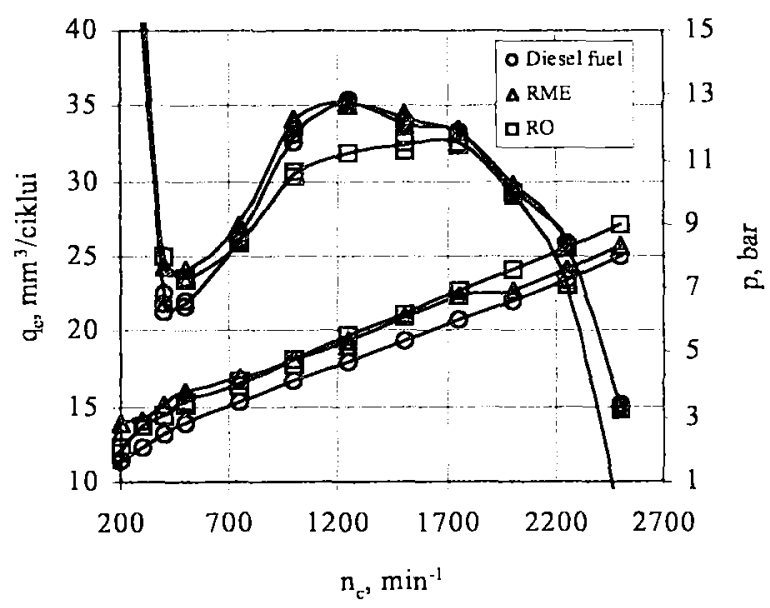

Fig 4. Governor characteristics of a distributor type fuel injection pump VE 4/9

In spite of different design of the tested injection pumps, the viscosity influence on the biofuel delivery rate in a governor control zone goes towards minimum. It can be related with a diminished quantity of the fuel to be injected per stroke at the engine top no-load speed and correspondingly that the chambers above the plungers may be charged only partially.

\section{Conclusions}

1. In the case of an in-line injection pump UTN-5 the increase of the fuel kinematic viscosity from 3,6 (diesel fuel) to $15,8 \mathrm{~mm}^{2} / \mathrm{s}$ (RME) leads to an average increase of fuel delivery per stroke $2,6 \%$. The same biofuel viscosity variation in distributor type pumps ND-21/4 and VE 4/9 results in $2-9 \%$ boosted delivery rate.

2. However, if kinematic viscosity of the biofuel increases up to $80 \mathrm{~mm}^{2} / \mathrm{s}$ (pure RO), biofuel delivery per stroke decreases because of worse high-pressure chamber above plunger charging conditions that greatly influence in the case of a distributor type injection pump ND-21/4 $(7,1-$ $24,7 \%$ ).

3. After the camshaft revolution frequency reaches the engine rated speed and exceeds it (governor action zone) the influence of fuel kinematic viscosity (except pure RO) on the quantity of the fuel delivered per stroke becomes less noticeable. In spite of different design it is a common feature of all the tested fuel injection pumps

4. It may be worth taking into account the given fuel temperature/viscosity relationship and viscosity influence on the injection rate adjusting different design of fuel injection pumps for their performance on biofuel.

5. The analysis of the given testing results shows that in line fuel injection pumps can be more suitable than distributor ones for the performance on viscous biofuel. In this case their adjusting procedures could be minimal.

\section{References}

1. Peterson C. L., Corada M. E., Sofley L. M., Broder J. D. Potential production of agriculturally produced fuels. Applied Engineering in Agriculture, Vol 11, No 6, 1995, p 767772.

2. Ali Y., Hanna M. A. Alternative diesel fuels from vegetable oils. Bioresource Technology, No 50, 1994, p 153-163.

3. Peterson C. L, Wagner G. L. Auld D. L. Vegetable oil substitutes for diesel fuel. Transactions of the ASAE, Vol 26, No 2, 1983, p 322-327.

4. Labeckas G., Slavinskas $S$. The research of biofuels usage in diesel engine. In: International conference Transbaltika -99 proceedings (Biodegalı naudojimo dyzeliniame variklyje tyrimas. Tarptautinès konferencijos Transbaltica -99 mokslinių pranešimų rinkinys). V.: Technika, 1999, p 409415 (in Lithuanian).

5. Astachov I. V., Golubkov L. N, Trusov V. I, Chachijan A. S., Riabikin L. M. The fuel systems and economy of diesel engines (Топливные системы и экономичность дизелей). Moscow: Machinostrojenije, 1990. 288 p (in Russian).

6. Urlaub A. Internal Combustion Engines: Basics, Performance theory, Structure (Verbrennungsmotoren: Grundlagen, Verfahrenstheorie, Konstruktion). Berlin Heidelberg: Springer, 1995. $570 \mathrm{p}$ (in Germany).

7. ISO 3104: 1994 Petroleum Products - Transparent and opaque liquids - Determination of kinematic viscosity and calculation of dynamic viscosity, 2000.13 p. 